\title{
Effects of Ketoprofen Administration on Relation between Acute Phase Proteins and Metabolic Parameters in Cows during Early Lactation
}

\author{
Zorana Kovacevic, Branislava Belic, Marko Cincovic, Nenad Stojanac, \\ Ognjen Stevancevic, Mihajlo Erdeljan, Ivana Davidov \& Dragica Stojanovic
}

\begin{abstract}
Background: Acute phase proteins (APPs) are clinically useful parameters for measuring the occurrence and severity of inflammatory responses in cattle. As large group of proteins, APPs are mainly secreted by hepatocytes whose concentration increase or decrease as response to tissue injury, inflammation or infection. The transition from late pregnancy to early lactation is associated with a compromised immune status coupled with increased acute phase response. Non-steroidal anti-inflammatory drugs (NSAIDs) are used in treatment of inflammatory conditions. The main objective of the present study was to analyze the effects of a preventive administration of the NSAID (ketoprofen) in post-calving dairy cows on concentration of APPs (haptoglobin and fibrinogen) and their relationship with indicators of liver function.

Materials, Methods \& Results: The treatment group $(\mathrm{n}=15)$ was given an intramuscular injection of ketoprofen in the concentration of $3 \mathrm{mg} / \mathrm{kg}$ during three consecutive days after calving. The control group $(\mathrm{n}=15)$ was not treated with ketoprofen. Blood samples were taken from coccygeal vein, on the first day of treatment and in the first and second week postpartum and they were analyzed for metabolic parameters (albumin and aspartat aminotransferaze) and APPs such as haptoglobin and fibrinogen. Compared with control, ketoprofen administration decrease the levels of haptoglobin and fibrinogen and AST activity. Increase in albumin concentration was recorded in experimental group of cows compared with control. Negative correlations $(P<0.01)$ were found between the haptoglobin concentration and albumin concentration and aspartate aminotransferaze activity.

Discussion: As inflammatory indicator in dairy cows, it is recorded that serum concentrations of haptoglobin is increased during mastitis. Beside haptoglobin, fibrinogen represents one of the APPs whose serum concentration increases during response in the acute phase. During the first and second week after partus, in cows with acute puerperal metritis, an increase in fibrinogen concentration was observed in relation to clinically healthy animals. Based on our results, it can be concluded that an intramuscular injection of ketoprofen $(3 \mathrm{mg} \times \mathrm{kg}$. bw.-1) administered in cows in the first days following parturition reduces the concentration of some APPs (haptoglobin and fibrinogen). In regard to Hp concentration, the treatment success agreed with previous results using i.m. acetyl-lysine salicylate during the first 5 days of lactation. Reduction in APPs concentration in our research results could be attributed to the anti-inflammatory effect of ketoprofen. In addition, use of ketoprofen reduces the intensity of relationship between inflammatory markers and indicators of liver function. Impaired functional capacity of the liver may be associated with reduced albumin concentration in the peripartal period, and during inflammatory or infectious diseases. Increase in albumin concentration in experimental group of cows compared to the control in our research could be attributed to the anti-inflammatory effect of ketoprofen. Hence it can be concluded that the use of ketoprofen immediately after calving reduces the intensity of relationship between inflammatory marker liver function and that NSAID treatment could be used in in improving animal well-being and controlling of the occurence and intesity of postpartum diseases.
\end{abstract}

Keywords: NSAID, haptoglobin, fibrinogen, BHBA, NEFA.

DOI: $10.22456 / 1679-9216.91667$ 


\section{INTRODUCTION}

During transition period cows enter a period of negative energy balance when nutrient demands for lactation exceed nutrient intake [7] with high levels of non-esterified fatty acids (NEFA) derived from adipose tissue triacylglycerol catabolism [4,21,27]. State of reduced function and fat accumulation in the liver experiences is coupled with increased acute phase response during peripartal period characterized with secretion of a large group of proteins, called acute phase proteins (APPs) [1] whose plasma concentration increase or decrease as response to tissue injury, inflammation, stress, trauma or infection [24]. Haptoglobin (Hp) represents the most studied APP in detection of diseases in cattle as a clinically useful parameter for measuring the occurrence and severity of inflammatory responses $[8,12,26]$. Beside $\mathrm{Hp}$, fibrinogen represents one of the APPs whose serum concentration increases during response in the acute phase [15].

Non-steroidal anti-inflammatory drugs (NSAIDs) are frequently used in human and veterinary medicine in treatment of pain and wide range of indications such as inflammatory conditions $[13,18,22]$. Use of ketoprofen is currently licensed for cows in the European Union at a dose rate of $3 \mathrm{mg} / \mathrm{kg}$ body weight [10]. Although ketoprofen has been indicated in cows for almost 20 years, there have been few reports on its clinical efficacy $[3,6,19]$.

The aim of the present study was to analyze the effects of a preventive administration of ketoprofen in post-calving dairy cows. This analysis may contribute to a better understanding of the changes in transition period including correlation between APPs and indicators of liver function.

\section{MATERIALS AND METHODS}

\section{Experimental animals, drug administration and sample collection}

The study was conducted on 30 HolsteinFriesian multiparous dairy cows in second and third lactation (3 - 4-year-old), located at the commercial dairy farm in Banatska Topola, Serbia. The selected cows were in the postpartum period, in a normal body condition (scored from 3.25 to 3.50 ), clinically healthy and with no clinical symptoms of any metabolic disorders, mastitis and retention of fetal membrane and remain clinically healthy throughout the study period.
Cows were daily monitored by veterinarians in first and second week of lactation.

The experimental cows $(n=15)$ were treated with ketoprofen whereas control cows $(n=15)$ were not treated. Experimental cows were treated with ketoprofen from the first day after calving for another three consecutive days with $3 \mathrm{mg} \times \mathrm{kg}$. bw. -1 ketoprofen given with IM injection. The mixture of vitamin $\mathrm{C}$ (vol. $10 \mathrm{~mL}$, dose $1.000 \mathrm{mg}$ ) and rehydration agent (Saline solution, $500 \mathrm{~mL}$ ) was applied to all cows by parenteral route (slow i.v.) and thus, all of them were exposed to the same stress, due to application of the drug, and there was no need to apply a placebo to the control group in order to ensure an identical impact of stress for both groups. The blood samples were taken from the coccygeal vein three times: on the day of calving, at the end of the first week (on day 7) and the second week (on day 14) after parturition. The samples were collected using sterile vacuum tubes ${ }^{1}$ containing EDTA for biochemical analyses.

\section{Measurement of metabolic parameters and acute phase proteins}

Metabolic parameters (albumin and AST) were determined by using the colorimetric reaction according to the manufacturer's instructions using Colorimetric $\mathrm{Kits}^{2}$, they were measured by means of the semi-automatic biochemistry analyzer ${ }^{3}$. The concentrations of acute phase proteins (haptoglobin and fibrinogen) were determined by the ELISA method, according to the standard manufacturer's instructions using Colorimetric Kits ${ }^{4}$.

\section{Statistical analysis}

The difference in the concentration of the metabolic parameters and acute phase proteins (mean \pm SD) in ketoprofen treated cows, in comparison to the control group, was determined using $t$-test. The statistical comparison of the groups was carried out by Statgraphics ${ }^{\circledR}$ Centurion XVII software and Microsoft Excel. The data analysis was performed using SPSS, version 19.0, software package for Microsoft Windows ${ }^{5}$. Compared results with $P<0.05$ were considered as statistically significant. Differences in the correlation test between acute phase proteins and metabolic parameters in experimental and control group of cows were determined by the Fischer r-to-z transformation test. Linearity is tested in all 45 samples of the experimental and control group (15 cows x 3 weeks). 


\section{RESULTS}

profen in the first days following parturition was efficient in a reduction in the concentration of $\mathrm{Hp}(P<$ $0.05)$ in the experimental group of cows compared to the control, in the first and second week after the partus (Figure 1). Fibrinogen concentration was significantly $(P$ $<0.05)$ lower in the second week after partus in experimental group of cows compared to the control (Figure 2). Our results showed increase in albumin concentration in

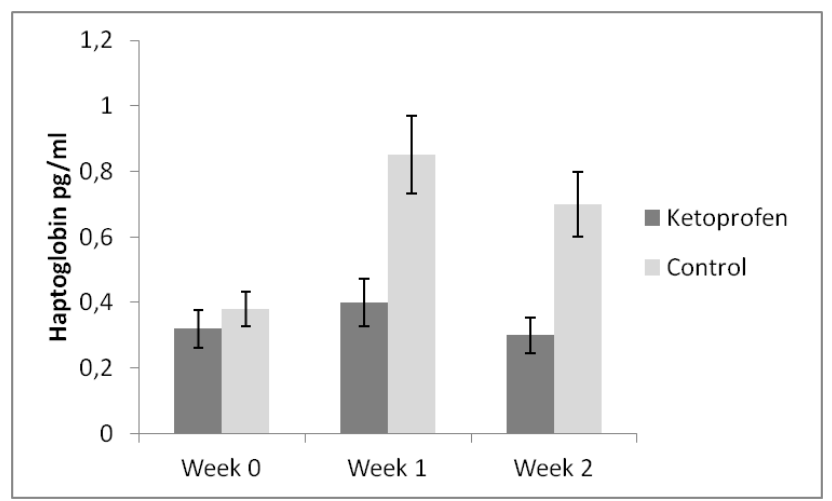

Figure 1. Influence of ketoprofen application on haptoglobin concentration.

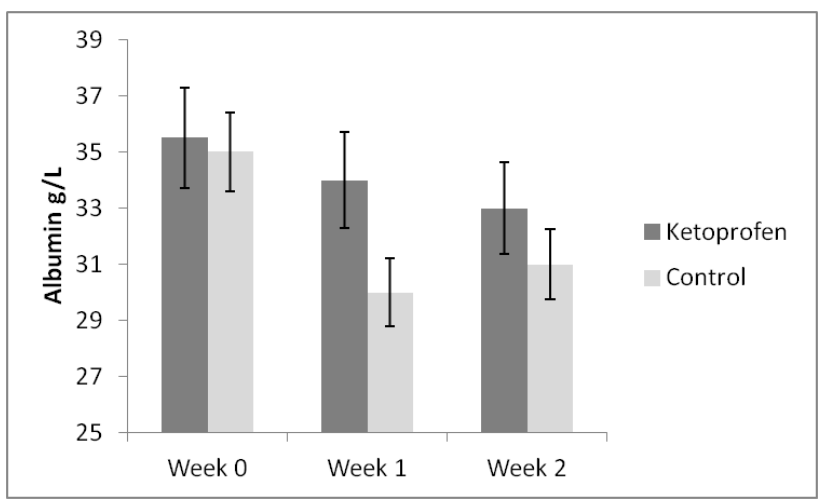

Figure 3. Influence of ketoprofen application on albumin concentration. experimental group of cows compared to the control, in the first and second week after the partus (Figure 3). We found that AST activity was lower in ketoprofen treated cows than in control group (Figure 4). In the assessment of correlations between the haptoglobin, significant negative correlation $(P<0.01)$ were found between the haptoglobin concentration and albumin concentration and aspartate aminotransferaze activity (Table 1). This correlation was lower in ketoprofen treated cows.



Figure 2. Influence of ketoprofen application on fibrinogen concentration.

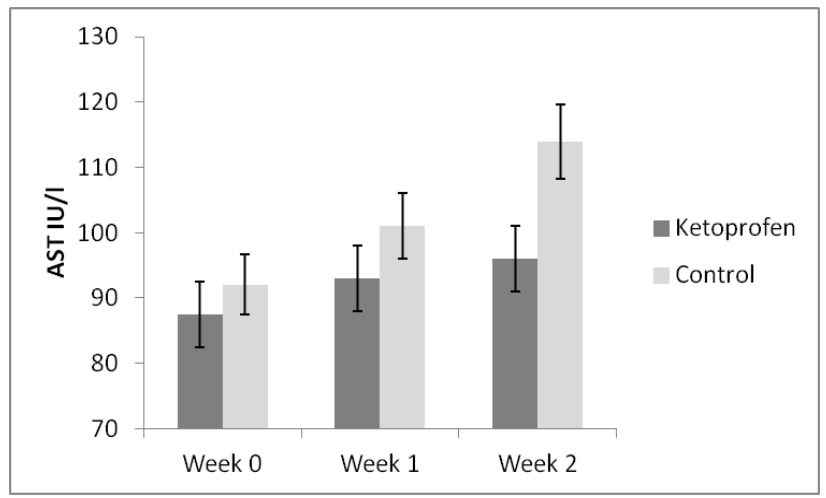

Figure 4. Influence of ketoprofen application on AST activity.

Table 1. The impact of ketoprofen application on the intensity of correlation between acute-phase proteins and biochemical parameters.

\begin{tabular}{cccc}
\hline & & \multicolumn{2}{c}{ Correlation } \\
\cline { 3 - 4 } & & Haptoglobin & Fibrinogen \\
\hline \multirow{2}{*}{ Albumin } & Ketoprofen & $-0.44^{*}$ & -0.29 \\
& Control & $-0.69^{*}$ & -0.30 \\
& $P$ & $<0.01$ & $\mathrm{NS}$ \\
\hline \multirow{2}{*}{ AST } & Ketoprofen & $0.78^{*}$ & 0.28 \\
& Control & $0.56^{*}$ & 0.28 \\
& $P$ & $<0.01$ & $\mathrm{NS}$ \\
\hline
\end{tabular}

*Correlation is statistically significant minimum $P<0.01$. 


\section{DISCUSSION}

As inflammatory indicator in dairy cows, it is recorded that serum concentrations of $\mathrm{Hp}$ is increased during mastitis [14,20]. In regard to Hp concentration, the treatment success agreed with previous results using i.m. acetyl-lysine salicylate during the first 5 days of lactation [5,30]. According to Jeremejeva et al. [16], during the first and second week after partus, in cows with acute puerperal metritis, an increase in fibrinogen concentration was observed in relation to clinically healthy animals. Reduction in APPs concentration in our research results could be attributed to the antiinflammatory effect of ketoprofen.

As one of the major APPs, Hp synthesis and secretion by the liver is regulated by the combined effect of cytokines and glucocorticoids [2]. Actually, one of the effects of cytokines is to trigger the synthesis of positive APPs (Hp, fibrinogen, C-reactive protein and serum amyloid A), and to reduce the synthesis of negative APPs (albumin, prealbumin, retinol binding protein and transferin) [9,23]. Our results are in accordance with this findings because we found negative correlation between $\mathrm{Hp}$ and albumin, significantly lower in ketoprofen treated cows than in control group. Besides, impaired functional capacity of the liver may be associated with reduced albumin concentration in the peripartal period [29]. In addition, the secretion of albumin was reduced during inflammatory or infectious diseases [11]. Increase in albumin concentration in experimental group of cows compared to the control in our research could be attributed to the anti-inflammatory effect of ketoprofen since inflammation is the principal cause of a decrease in serum albumin concentration.

Sun et al. [28] found that high AST was associated with impaired liver function in postpartum dairy cows. Lower AST activity in ketoprofen treated cows than in control group may be related with antiinflammatory efects of NSAID used in experiment. High Hp concentration was associated with AST enzyme activity as marker of impaired liver function [25].
Hp serum concentrations and activity of AST tended to be greater in cows with left displaced abomasum compared to their healthy counterparts [17]. Besides, high Hp concentrations 1 week after calving might also impared liver function, reflected by changes in enzyme concentration and associated with a higher incidence of peri- and postpartum disorders [28]. These findings comply with our findings where we found significantly stronger decrease correlation between $\mathrm{Hp}$ concentration and AST activity in ketoprofen-treated cows compared to the control group.

\section{CONCLUSIONS}

Based on our results, it can be concluded that an intramuscular injection of ketoprofen $(3 \mathrm{mg} \times \mathrm{kg}$. bw. $\left.^{-1}\right)$ administered in cows in the first days following parturition reduces the concentration of some APPs (haptoglobin and fibrinogen) and that use of ketoprofen reduces the intensity of relationship between inflammatory markers and indicators of liver funcition. Additionally, NSAID treatment could be used in in improving animal well-being and controlling of the occurence of postpartum diseases, but further investigations regarding ketoprofen influence on proinflammatory cytokine concentration are needed.

\section{MANUFACTURERS}

${ }^{1}$ BD Plymouth. Plymouth, UK.

${ }^{2}$ Randox Laboratories Ltd. London, UK.

${ }^{3}$ Rayto Electronics Inc. Shenzhen, China.

${ }^{4}$ Cloud-Clone Corp. Houston, TX, USA.

${ }^{5}$ IBM. Armonk, NY, USA.

Funding. This research was financed by the Ministry of Science and Technological Development, Republic of Serbia, [Grant number TR 31062].

Ethical approval. All procedures were approved by the decision, number 01-90/11-4, of the Ethical Committee of the University of Novi Sad, in order to safeguard the welfare of experimental animals.

Declaration of interest. The authors report no conflicts of interest. The authors alone are responsible for the content and writing of the paper.

\section{REFERENCES}

1 Ametaj B.N., Bradford B.J., Bobe G., Nafikov R.A., Young J.W. \& Beitz D.C. 2005. Strong relationships between mediators of the acute phase response and fatty liver in dairy cows. Journal of Animal Science and Technology. 85: 165-175.

2 Banmann H., Prowse K.R., Marinkovic S., Won K.-A. \& Jahreis P. 1989. Stimulation of hepatic acute phase response by cytoldnes and gluco-corticoids. Annals of the New York Academy of Sciences. 557: 280-295. 
3 Banting A., Banting S., Heinonen K. \& Mustonen K. 2008. Efficacy of oral and parenteral ketoprofen inlactating cows with endotoxin-induced acute mastitis. Veterinary Record. 163: 506-509.

4 Bernabucci U., Ronchi B., Lacetera N. \& Nardone A. 2005. Influence of body condition score on relationships between metabolic status and oxidative stress in periparturient dairy cows. Journal of Dairy Science. 88(6): 2017-2026.

5 Bertoni G., Trevisi E. \& Piccioli-Cappelli F. 2004. Effects of acetyl-salicylate used in post-calving of dairy cows. Veterinary Research Communications. 28: 217-219.

6 Donalisio C., Barbero R., Cuniberti B., Vercelli C. \& Casalone M.R. 2013. Effects of flunixin meglumine and ketoprofen on mediator production in ex vivo and in vitro models of inflammation in healthy dairy cows. Journal of Veterinary and Pharmacology and Therapeutics. 36(2): 130-139.

7 Drackley J.K., Overton T.R. \& Douglas G.N. 2001. Adaptations of glucose and long- chain Fatty acid metabolism in liver of dairy cows during the periparturient period. Journal of Dairy Science. 84 (E.Suppl.): E100-E112.

8 Earley B. \& Crowe M.A. 2002. Effects of ketoprofen alone or in combination with local anesthesia during the castration of bull calves on plasma cortisol, immunological and inflammatory responses. Journal of Animal Science. 80: 1044-1052.

9 Eckersall P.D. \& Bell R. 2010. Acute phase proteins: Biomarkers of infection and inflammation in veterinary medicine. Veterinary Journal. 185: 23-27.

10 European Agency for the Evaluation of Medicinal Products, Veterinary Medicines Evaluation Unit (EMEA/ MRL/020/95) - 1995 Committee for Veterinary Medicinal Products (Ketoprofen). 1995. Summary Report. http:// www.ema.europa.eu/docs/en_GB/document_library/Maximum_Residue_Limits_-_Report/2009/11/WC500014541. pdf [Accessed online November 2018]. 11 Evans T.W. 2002. Review article: albumin as a drug: biological effects of albumin unrelated to oncotic pressure. Alimentary Pharmacology and Therapeutics. 16(5): 6-11.

12 Fisher A.D., Knight T.W., Cosgrove G.P., Death A.F., Anderson C.B., Duganzich D.M. \& Matthews L.R. 2001. Effects of surgical or banding castration on stress responses and behavior of bulls. Australian Veterinary Journal. 79: 279-284.

13 Green G.A. 2001. Understanding NSAIDs: from aspirin to COX-2. Clinical Cornerstone. 3(5): 50-60.

14 Grönlund U., Hallen Sandgren C. \& Persson Waller K. 2005. Haptoglobin and serum amyloid A in milk dairy cows with chronic sub-clinical mastitis. Veterinary Research. 36(2): 191-198.

15 Hayes M.A. 1994. Functions of cytokines and acute phase proteins in inflammation. In: VIth Congress of the International Society for Animal Clinical Biochemistry, Proceedings of the Congress-International Society for Animal Clinical Biochemistry, University of Guelph (Guelph Canada). pp.1-7.

16 Jeremejeva J., Orro T. \& Kask K. 2015. Relationship between acute phase proteins and subsequent fertility of dairy cows after postpartum uterine inflammation and healthy cows. Veterinary Medicine and Zootehnics. 70(92): 37-41.

17 Klevenhusen F., Humer E., Metzler-Zebeli B., Podstatzky-Lichtenstein L., Wittek T. \& Zebeli Q. 2015. Metabolic Profile and Inflammatory Responses in Dairy Cows with Left Displaced Abomasum Kept under Small-Scaled Farm Conditions. Animals. 5(4): 1021-1033.

18 Lees P., Landoni M.F., Giraudel J. \& Toutain P.L. 2004. Pharmacodynamics and pharmacokinetics of nonsteroidal antiinflammatory drugs in species of veterinary interest. Journal of Veterinary and Pharmacology and Therapeutics. 27: 479-490.

19 Newby N.C., Pearl D.L., Le Blanc S.J., Leslie K.E., Keyserlingk M.A.G. \& Duffield T.F. 2013. The effect of administering ketoprofen on the physiology and behavior of dairy cows following surgery to correct a left displaced abomasum. Journal of Dairy Science. 96(3): 1511-1520.

20 Ohtsuka H., Koiwa M., Hatsugaya A., Kudo K., Hoshi F., Itoh N., Yokota H., Okada H. \& Kawamura S. 2001. Relationship between serum TNF activity and insulin resistance in dairy cows affected with naturally occurring fatty liver. Journal of Veterinary Medicine Science. 63: 1021-1025.

21 Reynolds C.K., Aikman P.C., Lupoli B., Humphries D.J. \& Beever D.E. 2003. Splanchnic metabolism of dairy cows during the transition from late gestation to early lactation. Journal of Dairy Science. 86: 1201-1217.

22 Pardon B., Catry B., Dewulf J., Persoons D., Hostens M., Bleecker K.D. \& Deprez P. 2012. Prospective study on quantitative and qualitative antimicrobial and anti-inflammatory drug use in white veal calves. Journal of Antimicrobial Chemotherapy. 67: 1027-1038.

23 Petersen H.H., Nielsen J.P. \& Heegaard P.M. 2004. Application of acute phase protein measurements in veterinary clinical chemistry. Veterinary Research. 35: 163-187. 
24 Ruminy P., Gangneux C., Claeyssens S., Scotte M., Daveau M. \& Salier J.P. 2001. Gene transcription in hepatocytes during the acute phase of a systemic inflammation: from transcription factors to target genes. Inflammation Research. 50: 383-390.

25 Shin D.H., Jeong J.K., Choi I.S., Moon S.H., Lee S.C., Kang H.G., Park S.B. \& Kim I.H. 2018. Associations between serum haptoglobin concentration and peri-and postpartum disorders, milk yield, and reproductive performance in dairy cows. Livestock Science. 213: 14-18.

26 Skinner J.G., Brown R.A.L. \& Roberts L. 1991. Bovine haptoglobin response in clinically defined field conditions. Veterinary Record. 128: 147-149.

27 Sordillo L.M., Contreras G.A. \& Aitken S.L. 2009. Metabolic factors affecting the inflammatory response of periparturient dairy cows. Animal Health Research Reviews. 10: 53-63.

28 Sun Y., Wang B., Shu S., Zhang H., Xu C., Wu L. \& Xia C. 2015. Critical thresholds of liver function parameters for ketosis prediction in dairy cows using receiver operating characteristic (ROC) analysis. Veterinary Quarterly. 35(3): 159-164.

29 Trevisi E., Ferrari A., Archetti I. \& Bertoni G. 2005. Anti-inflammatory treatments in calving dairy cows: effects on haematological and metabolic profiles. Italian Journal of Animal Science. 4(2): 203-205. 